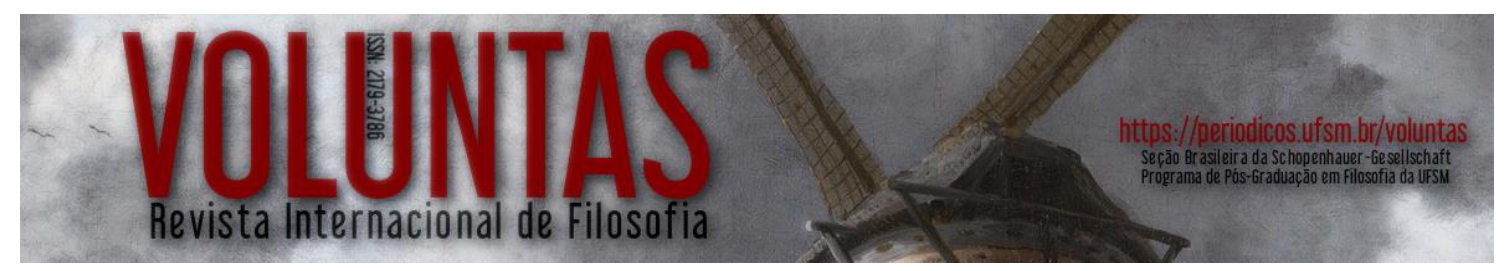

ISSN: 2179-3786

DOI: $10.5902 / 2179378636052$

\title{
Pessimismo e política: conservadorismo e crítica social a partir de Schopenhauer ${ }^{1}$
}

Pessimism and politics: conservatism and social criticism based on Schopenhauer

\author{
Flamarion Caldeira Ramos \\ Professor da Universidade Federal do $A B C$ \\ Coordenador do GT Schopenhauer da ANPOF \\ E-mail: flamarioncr@yahoo.com.br
}

Resumo: A relação entre política e pessimismo, ou mais precisamente, entre a possibilidade de mudança social e política, por um lado, e a rejeição metafísica dessa mesma possibilidade, por outro, tem sido marcante na recepção da filosofia de Schopenhauer desde o século dezenove. Por um lado, uma vasta gama de autores mobilizará argumentos pessimistas que ou coincidem ou se inspiram em Schopenhauer para defender uma perspectiva imobilista e conservadora da política e, por outro, vários autores se valerão de argumentos presentes na filosofia de Schopenhauer como uma denúncia das condições de iniquidade e injustiça da vida nas sociedades modernas capitalistas. Por essa razão, é possível de fato destacar tanto uma "direita schopenhaueriana" quanto uma "esquerda schopenhaueriana". No presente artigo procurarei apresentar um quadro geral da recepção da filosofia de Schopenhauer no que diz respeito ao ideário propriamente político, partindo de uma análise do vínculo entre seu pessimismo e sua filosofia política e desembocando nos diversos usos do pessimismo feitos para justificar as mais diversas posições políticas.

Palavras-chave: Pessimismo; Política; Conservadorismo; História; Solidariedade.

Abstract: The relationship between politics and pessimism, or more precisely, between the possibility of social and political change on the one hand, and the metaphysical rejection of that possibility on the other, has been striking in the reception of Schopenhauer's philosophy since the nineteenth century. On the one hand, a wide range of authors will mobilize pessimistic arguments that either coincide or are inspired by Schopenhauer to defend an immobilist and conservative perspective of politics and, on the other hand, several authors will use arguments present in the philosophy of Schopenhauer as a denunciation of the conditions of injustice in modern capitalist societies. For this reason, it is possible to emphasize both a "Schopenhauerian right" and a "Schopenhauerian left". In the present article, I will try to present a general picture of the reception of Schopenhauer's philosophy as far as the ideology is concerned. It is based on an analysis of the link between his pessimism and his political philosophy and leads to the various uses of pessimism made to justify the most diverse positions.

\footnotetext{
${ }^{1}$ O leitor do presente artigo verá que minha proposta é contrária à leitura que tem sido recorrente na recepção brasileira da filosofia de Schopenhauer de recuperação de sua eudemonologia, abordagem essa que tornaria possível um uso prático de seu pensamento, proposta que tem sido caracterizada como "esquerda schopenhaueriana". A divergência se dá na medida em que uso a distinção "direita e esquerda" em seu significado original, político. Para uma apresentação dessa outra perspectiva, remeto ao artigo de Felipe Durante, publicado no número anterior da Revista Voluntas sob o título A esquerda schopenhaueriana no Brasil. Ao debater alguns textos de Felipe Durante em diversas ocasiões, pude tornar mais clara para mim mesmo a minha divergência. Por isso, dedico ao Prof. Felipe Durante o presente artigo, em forma de agradecimento.
}

Voluntas: Revista Internacional de Filosofia - periodicos.ufsm.br/voluntas - Santa Maria - Vol. 9, n. 2, jul.-dez. 2018, p. 35-53. 
Key-words: Pessimism; Politics; Conservatism; History; Solidarity.

"É que o anzol da direita fez a esquerda virar peixe" (Criolo, "Esquiva da esgrima". In: Convoque seu Buda, 2015)

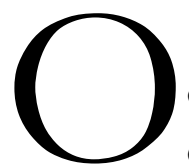

pessimismo está na ordem do dia. Ele está na base tanto daqueles que se colocam deliberadamente "contra um mundo melhor", como comparece enquanto visão crítica que percebe para além da aparente normalidade um processo perverso de deterioração moral e política. Seja do ponto de vista conservador, seja de um ponto de vista progressista ou crítico, o pessimismo parece estar mais próximo da realidade do que qualquer tipo de visão utópica e otimista sobre o atual curso do mundo, visão em geral abandonada até mesmo por aquela corrente filosófica construída em torno da ideia de revolução, isto é, o marxismo. Isso não significa, porém, uma atualidade da filosofia de Schopenhauer, como se ela voltasse a gozar do prestígio que teve na Europa na segunda metade do século dezenove, pois embora seja ele a maior referência do pessimismo filosófico, nem sempre as principais correntes da filosofia contemporânea estabeleceram um vínculo fundamental com o autor de $O$ mundo como vontade e representação. Entretanto, é sempre possível perceber, ainda que obscurecido pela sombra do hegelianismo, algum vestígio do olhar de Schopenhauer para o mundo em meio às mais diversas vertentes da filosofia contemporânea. Por isso, Schopenhauer, mesmo sendo já clássico, permanece de alguma forma atual, ou, retomando as palavras de Clement Rosset, é um pensador "muito moderno para ser clássico e muito clássico para ser moderno"2.

Essas palavras servem para justificar o que segue, a saber, um pequeno esboço de uma pesquisa sobre um tema bastante amplo: a relação entre pessimismo e política. Em que medida uma convicção fundamentalmente pessimista sobre o ser, a natureza ou o curso do mundo humano justificaria uma posição política, conservadora ou crítica-progressista? O pessimismo é, de fato, capaz de fundamentar um conservadorismo, na medida em que em grande medida suas conclusões são de fato antimodernas, anti-iluministas e contrarrevolucionárias? Seria possível conciliar uma convicção fundamentalmente pessimista com uma perspectiva iluminista, crítica e progressista que procuraria ao menos diminuir a soma total de sofrimento no mundo? Ou de fato, a necessidade de criação das condições teóricas e práticas para a superação da dominação do homem sobre o homem levaria ao abandono das convicções pessimistas? As linhas que seguem pretendem apenas oferecer alguns caminhos para o confronto com tal questionamento.

\footnotetext{
2 ROSSET, Schopenhauer, Philosophe de L'absurde. Paris: PUF, 1967, p. 60.
} 


\section{Sobre o conceito de pessimismo}

Em primeiro lugar, devemos nos resolver com a definição do conceito vago e genérico de "pessimismo". Embora a palavra esteja já associada à filosofia de Schopenhauer, o próprio nunca definiu sua metafísica como "pessimista" e usou a expressão em poucas passagens de sua obra. De fato, "pessimismo" aparece como um conceito filosófico mais preciso a partir da discussão da assim chamada "escola schopenhaueriana", ou seja, após a morte do filósofo de Danzig. Sobretudo os escritos de Eduard von Hartmann popularizaram o pessimismo e vincularam a recepção da filosofia de Schopenhauer a esse conceito. Dessa forma, podemos observar uma persistência do debate em torno do pessimismo em quase toda produção da "escola de Schopenhauer", desde o livro de Hartmann Zur Geschichte und Begründung des Pessimismus de 1880 até a conferência Pessimismus Heute de Horkheimer de 1969. Não teremos espaço neste artigo para abordar o problema do pessimismo em todas as suas expressões (que perpassam, por exemplo, a discussão entre os "metafísicos" da escola schopenhaueriana - Hartmann, Bahnsen e Mainländer, e as filosofia de Nietzsche, Spengler e Cioran, entre outros). Nos restringiremos a esboçar o conceito de pessimismo em Schopenhauer e a partir dele os usos e abusos do pessimismo em perspectiva política.

Podemos falar em pelo menos três momentos da obra de Schopenhauer em que se pode extrair uma filosofia pessimista, ou mesmo uma definição de pessimismo, embora ele mesmo não a ofereça. O primeiro momento é a negação do otimismo leibniziano contido em sua Teodicéia e em sua teoria do "melhor dos mundos possíveis"; o segundo, a descrição da vida em geral e da vida humana em particular que constitui a ética e que se funda, por sua vez, na tese metafísica que afirma que "toda vida é sofrimento"; e, por fim, a caracterização de uma certa hierarquia entre as religiões pela medida do pessimismo (verdade) ou otimismo (ilusão). Destaco esses como os momentos principais, sendo possível, porém, encontrar outros que, contudo, estarão subordinados a algum desses três pontos.

No sistema de Schopenhauer a vontade não é somente a raiz metafísica do mundo, mas também a fonte de todos os sofrimentos. Ela é cega, irracional e sem finalidade. A felicidade e o prazer são considerados meramente negativos, pois residem em momentos transitórios de satisfação do querer, que são imediatamente seguidos por novas solicitações do querer insaciável. A vida humana é assim descrita como um pêndulo que oscila constantemente entre a dor - incapacidade de satisfazer o querer - e o tédio - quando o querer não encontra objeto de satisfação. Ao homem só restaria então buscar uma saída nos momentos de silêncio da vontade, na contemplação objetiva do belo natural e artístico e na experiência mística da negação da vontade. 
De acordo com isso, não poderia deixar de haver uma crítica insistente contra o otimismo sob todas as suas formas: não só contra a filosofia de Leibniz e a doutrina do meilleur des mondes possibles, como também contra todas as suas manifestações modernas (segundo Schopenhauer), como a ética kantiana, a teoria rousseauísta da perfectibilidade humana, o idealismo alemão, em especial a filosofia de Hegel, o panteísmo e a redescoberta de Espinosa pelos alemães. O otimismo, diz o autor,

\begin{abstract}
quando não é meramente o discurso sem pensamento de pessoas cujas cabeças ocas estão preenchidas por meras palavras, não é somente um absurdo, mas aparece na verdade também como um modo de pensamento perverso, como uma profunda ironia sobre os inomináveis sofrimentos da humanidade. Não se deve pensar que a doutrina de fé cristã seja favorável ao otimismo, ao contrário, nos evangelhos as noções de mundo e mal são quase sempre empregadas como sinônimas (W I, \59, p. 385, Trad. p. 378-379).
\end{abstract}

Contra o clássico argumento da inefetividade do mal, ou de sua compensação pelo bem maior do todo, Schopenhauer opõe a simples presença do mal, empiricamente constatável, capaz de reduzir ao nada a aspiração humana de felicidade. Se compararmos a soma de todas as alegrias possíveis que um homem pode desfrutar em sua existência com aquela de todos os sofrimentos meramente possíveis que podem o atingir, vemos que para a felicidade há um limite; para o sofrimento, não. Mas a discussão sobre a proporção do bem e do mal no mundo é supérflua, pois o mal não pode ser apagado de forma alguma, ou compensado por um bem simultâneo ou posterior:

Com efeito, ainda que milhares tivessem vivido na felicidade e na volúpia, a angústia e a agonia mortal de um só indivíduo não seriam suprimidas; e meu bem estar presente não desfaz meus sofrimentos passados. Se houvesse no mundo cem vezes menos sofrimento do que há de fato, ainda assim a simples existência do mal seria suficiente para fundar aquela verdade, que se expressa de diversas formas, ainda que de forma sempre indireta, a saber, que nós temos muito menos a felicitar que a nos atormentar sobre a existência do mundo; - que o não ser de sua existência seria preferível - que é algo que, no fundo não deveria ser etc. (W II, Cap. 46, p. 661).

Como se vê, o fundamento da crítica ao otimismo da tradição racionalista da filosofia está na própria metafísica de Schopenhauer, em sua concepção de vontade. A descoberta da vontade como chave para a decifração do enigma do mundo é apresentada pelo filósofo no segundo livro de O Mundo como Vontade e Representação. Nele Schopenhauer apresenta sua metafísica da natureza, na qual a vontade se manifesta. Essa vontade, por ser independente da representação e do princípio de 
razão é cega e irracional. As formas racionais da consciência são meras aparências e a essência de todas as coisas seria alheia à razão, algo sem qualquer meta ou finalidade, um querer irracional e inconsciente. Segundo Schopenhauer, o erro fundamental em que caíram todos os filósofos anteriores repousa na visão de que o todo da natureza saiu de um intelecto, isto é, que a realidade é o resultado de um plano racionalmente elaborado. Para ele a natureza não é o resultado de um intelecto criador, mas o conhecimento já é um produto da natureza. É a Vontade que constitui o fundamento de todas as coisas. Objetivada no corpo essa Vontade se afirma na busca da satisfação das necessidades desse próprio corpo. Essa afirmação consiste na conservação do indivíduo e na propagação da espécie. A satisfação da necessidade sexual ultrapassa a afirmação da existência particular, limitada a um tempo tão curto, vai para além da morte do indivíduo, constitui assim a afirmação da vida infinita.

Dessa forma, apesar da unidade essencial da vontade em todas as suas manifestações, cada indivíduo se toma pelo centro de tudo, fazendo mais caso da sua existência e do seu bem-estar que dos de todo o resto. Este estado de alma é o egoísmo, e ele é essencial a todos os seres na natureza. Através desse fato, Schopenhauer constata a contradição íntima que a vontade tem consigo mesma: a vontade consiste num esforço que jamais atinge um alvo verdadeiro, uma satisfação final, em nenhuma parte um lugar de repouso, deseja sempre, sendo o desejo todo o seu ser. É por isso que só podemos conceber os seres do mundo num estado de perpétua dor, sem felicidade durável. Isso porque todo desejo é sofrimento, enquanto não é satisfeito, pois nasce duma falta. Como não existe fim último para o esforço, não existe termo para o sofrimento: toda vida é sofrimento [alles Leben Leiden ist] (W I, \ 56, p. 366).

A partir dessa impossibilidade de satisfação, dessa perpétua condenação ao desejo, Schopenhauer estabelece a célebre fórmula: "A vida oscila, portanto, como um pêndulo, para aqui e para acolá, entre a dor e o tédio" (W I, $\int 56$, p. 368). O movimento da vida está submetido ao movimento do desejo, e o desejo "tem por princípio uma necessidade, uma falta, logo uma dor”. A alegria humana é apenas uma felicidade negativa, a alegria de recusar a vontade e, assim, evitar os aborrecimentos. Enquanto dominado pela vontade, ele conhece apenas a oscilação entre o tédio e a dor. Portanto, para Schopenhauer, o sofrimento é o fundo de toda vida. Com esse raciocínio Schopenhauer afirma seu pessimismo e critica as filosofias racionalistas cristãs como as de Leibniz e Hegel que concebem a existência como a realização de uma ideia pré-estabelecida. Schopenhauer diz ainda, ironicamente, que este é na verdade não o "melhor dos mundos possíveis" (expressão de Leibniz na Teodicéia), e sim o pior dos mundos possíveis já que uma outra existência ainda mais precária não seria sequer concebível.

Apesar de tudo isso, Schopenhauer não chega a afirmar ipsis litteris que sua filosofia seja pessimista. Prefere, porém, apontar a superioridade dos sistemas 
religiosos em que a vida é julgada de maneira pessimista em comparação ao otimismo das religiões ditas por "inferiores". Isso bem poderia indicar que as caracterizações "pessimistas" ou "otimistas" teriam mais a ver com uma expressão não plenamente conceitual da verdade, como são os sistemas metafísicos, e sim com visões de mundo menos elaboradas conceitualmente, como são as religiões entendidas como "metafísica para o povo", nas quais a verdade, quando há, é expressa de maneira alegórica e não em sentido próprio como na metafísica. As religiões mais elogiadas por Schopenhauer são exatamente aquelas que estão de acordo com sua filosofia, e nesse contexto o autor aponta a superioridade delas em relação a outras exatamente pelo seu caráter pessimista. Aliás, esse é mesmo o critério para estabelecer uma hierarquia entre as religiões: "A diferença fundamental das religiões consiste em saber se são otimismo ou pessimismo; de modo algum se são monoteísmo, politeísmo, trimúrti, trindade, panteísmo ou ateísmo (como o budismo)" (P II, Cap. 15, \ 181). Dessa forma, as religiões mais elogiadas e consideradas mais próximas da verdade filosófica são o cristianismo (de acordo com as interpretações de Agostinho e Lutero), o budismo e o bramanismo. Schopenhauer elogia especialmente essas religiões orientais graças ao idealismo e ao pessimismo nelas presentes, pois atribuiriam ao mundo apenas uma existência onírica e considerariam a vida uma consequência de nossa culpa. É aventada até mesmo a hipótese da origem hindu do cristianismo. Já o judaísmo é acerbamente criticado pois possuiria, segundo o filósofo, como características principais, "o realismo e o otimismo, que são intimamente afins e são as condições do verdadeiro teísmo, já que esse apresenta o mundo material como absolutamente real e a vida como um agradável regalo feito para nós” (P II, Cap. 15, $\left.\int 179\right)^{3}$.

Não obstante todas as limitações do discurso racional, da ciência e da filosofia, Schopenhauer mantém-se afastado de uma queda na religião, e sua postura permanece, no fim das contas, "iluminista": a verdade não deveria assumir a roupagem da mentira pois assim ela entraria numa aliança perigosa (Cf. P II, Cap. 15, p. 355). Entre a exigência da verdade e a limitação da natureza finita da razão, Schopenhauer nem desiste da metafísica nem constrói um ponto de vista livre do caráter limitado do homem. Por isso sua filosofia oscila, como ele mesmo admite, "entre a doutrina da onisciência dos dogmáticos precedentes e o desespero da crítica kantiana" (W I, p. 507; Trad. p. 539). Mesmo com essas limitações o filósofo chega até a supor uma eventual eutanasia da religião, pela qual ela deixaria de ter lugar num futuro próximo deixando espaço para um discurso baseado apenas e tão somente na

\footnotetext{
${ }^{3}$ Nesse sentido, é constatada a superioridade do Novo testamento em relação ao Antigo. A crítica de Schopenhauer ao judaísmo é tão persistente que é difícil deixar de notar o anti-semitismo presente em algumas passagens, especialmente no $\int 177$ ao culpar o judaísmo pelo desprezo aos animais na cultura ocidental. Contudo, a discussão sobre o anti-semitismo de Schopenhauer é complexa e não se poderia acusar apressadamente Schopenhauer de inimigo dos judeus, como mostrou Henry Walter Brann em seu livro Schopenhauer und das Judentum.
} 
argumentação racional: "Os resultados morais do cristianismo, até a mais alta ascese, encontram-se em mim racionalmente fundamentados e em conexão com as coisas, ao passo que no cristianismo são fundamentados por meras fábulas. A fé no cristianismo desaparece cada dia mais e, por isso, se tem de recorrer à minha filosofia" (P I, p. 150) ${ }^{4}$.

Essa afirmação inequívoca sobre a superioridade da filosofia em relação à religião tornaria imprópria qualquer uso do pessimismo de Schopenhauer como arma para a defesa da fé em detrimento da razão. Por mais que, como veremos, a leitura conservadora do ponto de vista político da filosofia de Schopenhauer encontre quase sempre base textual, a rejeição da superstição e da autoridade do discurso religioso representa um limite evidente para esse tipo de apropriação.

\section{A filosofia politica de Schopenhauer}

Agora poderemos, enfim, abordar o tema central de nossa proposta, qual seja, o vínculo entre pessimismo e política. Cabe ver, em primeiro lugar, o que constitui a filosofia política de Schopenhauer e em que medida ela pode ser lida na chave do pessimismo. Em que sentido ela dá continuidade aos pressupostos metafísicos do seu sistema e qual o vínculo entre ela e sua ética que desemboca na doutrina da "negação da vontade de viver". A partir disso, estaremos em condições de discutir a pertinência das interpretações políticas de Schopenhauer, à direita e à esquerda.

Schopenhauer expõe o fundamental de sua teoria política no $\int 62$ de sua obra principal, ao descrever a passagem da afirmação para a negação da vontade (WI, \$S 60-68) ${ }^{5}$. A afirmação da vontade de viver no indivíduo pode conduzi-lo a negar a mesma vontade que se expressa no outro. É o egoísmo levado à sua mais extrema consequência a fonte da injustiça. A teoria schopenhaueriana da justiça se estabelece de forma negativa: a noção de algo injusto (Unrecht) é primitiva e positiva, e a de justiça é secundária e negativa. A injustiça é a invasão no domínio onde se afirma a vontade do outro: uma ação injusta é aquela que consiste na destruição ou ferimento do corpo do outro, ou então na redução das forças desse corpo ao seu próprio serviço; assim o injusto aumenta as forças ao seu serviço e ultrapassa essa soma de recursos que é seu próprio corpo, ele afirma a sua própria vontade para além dos seus próprios limites e o faz negando a vontade manifestada num corpo estranho. As ações justas são aquelas que não ultrapassam os limites traçados pela vontade do agente, limites estes que apaziguam seu egoísmo.

\footnotetext{
${ }^{4}$ Fragmentos para a história da filosofia, p. 120. Essa passagem é um acréscimo da edição póstuma dos Parerga e Paralipomena cuja origem é uma nota de 1856. Cf. HN IV, vol. 2, p. 311. Cf. P II, p. 365 (Sobre a Religião).

${ }^{5}$ Sua teoria política é fundamentada numa teoria do direito (Rechtslehre) que engloba as definições de justo e injusto e uma teoria do Estado, expressa em termos contratualistas. De acordo com a indicação do próprio Schopenhauer (W I, p. 410), sua pura doutrina do direito expressa no $\ 62$ pode ser dividida em cinco partes: I - Explanação do sentido íntimo e próprio e da origem dos conceitos de injusto e justo, bem como sua aplicação e lugar na moral (1-2); II - Dedução do direito de propriedade (3); III - Dedução da validade moral dos contratos (4 - 5); IV - Explanação da origem e do fim do Estado e da relação deste fim com a moral, assim como da transferência apropriada da doutrina moral do direito, por inversão, para a legislação $(6$ - 14) e V Dedução do direito penal $(15$ - 16). O último parágrafo tem como tarefa ainda mostrar a insuficiência do Estado e da política para garantir a satisfação da vontade (17).
} 
Schopenhauer critica Hobbes porque este teria negado a existência de um direito para além do Estado, isto é, teria concebido todo direito propriamente moral como convencional. Segundo Schopenhauer, Hobbes teria confundido o direito com os meios de fazê-lo valer ${ }^{6}$. Embora só possa haver garantia do direito no Estado, em si mesmo ele é independente dele, pois se o direito é violentado no estado de natureza ele não é, no entanto, jamais suprimido. Enquanto tal, porém, ele existe apenas na consciência, não vai além do indivíduo que o reconhece. Assim, a consciência não pode impedir que, no estado de natureza, a violência se estabeleça em vez do direito. No estado de natureza, depende de cada um e sempre não cometer injustiça, mas não depende em nenhum caso de cada um não sofrer injustiça, isso depende apenas da força exterior de cada um. Desse modo, ainda que por um lado, os conceitos de justo e injusto tenham valor independentemente da legislação estatal e não sejam convencionais, por outro, eles valem apenas como meros conceitos morais (blo $\beta$ als moralische Begriffe) e relacionam-se com o autoconhecimento que cada um possui de si. (Cf. W I, S 62, p. 403).

Graças à razão, os homens descobrem um meio de diminuir as dores inseparáveis da vida humana das quais o egoísmo é a causa, até quase suprimi-las na medida do possível. Este meio é um sacrifício comum, compensado por sua vez pelas vantagens comuns que se obtêm com ele. O egoísmo orientado pela razão descobre esse meio, e o aperfeiçoa na medida do possível: é enfim, o contrato social, a lei. Schopenhauer expõe então sua teoria do contrato social, como o modo universal em que surge o Estado, como uma maneira natural que o homem, com o desenvolvimento de sua razão, se relaciona com os outros homens. Para o filósofo, a razão, enquanto instrumento da Vontade, se eleva do ponto de vista do indivíduo até a perspectiva da universalidade e percebe que o prazer produzido num dos indivíduos pelo ato injusto é destruído por um sofrimento maior em proporção que se produz no outro. A razão "reconhece, a partir daí, que tanto para diminuir o sofrimento espalhado em toda parte quanto para reparti-lo da maneira mais equânime possível, o melhor e único meio é poupar a todos a dor relacionada ao sofrimento da injustiça, fazendo-lhes renunciar ao gozo obtido com sua prática. Esse meio, facilmente divisado e gradualmente aperfeiçoado pelo egoísmo, o qual, usando a faculdade de razão, procedeu metodicamente e abandonou o seu ponto de vista unilateral, é o contrato de Estado ou a le?" (W I, \ 62, p. 405).

Schopenhauer não concebe qualquer outra origem possível para o Estado. Independentemente das condições pelas quais esse contrato social é feito, o que faz aparecer o Estado é sempre o contrato consentido por todos. O Estado será considerado mais ou menos imperfeito conforme este contrato é mais ou menos alterado por uma mistura de elementos anárquicos ou despóticos. Para fundar um Estado perfeito, segundo o autor, seria preciso começar por fazer seres a quem a natureza permitisse sacrificar totalmente o seu bem particular ao bem público ${ }^{7}$.

\footnotetext{
${ }^{6}$ Schopenhauer desenvolve essa crítica no capítulo 47 dos "Complementos" à sua principal obra, O Mundo como Vontade e Representação (Cf. W II, p. 683).

7 A partir desse raciocínio, Schopenhauer argumenta em favor de sua preferência em relação ao regime monárquico. Se o regime misto, inventado para escapar respectivamente, da anarquia e do despotismo, acaba tendendo para o reino das facções, na monarquia o inconveniente da separação entre o bem público e o bem particular apresenta-se menos problemática: "nos aproximamos do alvo onde existe uma família cuja fortuna
} 
Apesar de estar fundado na moral, o Estado não pode transformar a vida em comum num paraíso moral. É certo que no Estado ideal cada um persegue o bem de todos, porque cada um sabe que seu próprio bem está envolvido naquele. Se ele alcança inteiramente seu objetivo, ele produzirá certamente a aparência de uma comunidade em que a moralidade perfeita reinasse sobre todas as ações. Mas há uma diferença fundamental entre a moralidade e o Estado que corresponde às finalidades distintas que perseguem. Enquanto a ética trata apenas das ações, e com relação a estas, a intenção com que ela foi realizada, a teoria do Estado tem em vista apenas a vítima da injustiça. Quanto ao autor, não se importaria com ele se ele não fosse o correlativo forçado da vítima. Para ela, o ato injusto é apenas o adversário contra o qual ela emprega os seus esforços.

Em Schopenhauer, o direito diz respeito à condição externa da moral, à "liberdade política" ou "física", e não à determinação da virtude. Por essa razão, "apenas o negativo, que é o direito, poder ser imposto, não o positivo, o qual se entendeu sob a rubrica de deveres de caridade ou deveres imperfeitos” (W I, \ 62, p. 409). Assim, Schopenhauer expressa uma divisão entre ética e direito bem próxima daquela que Kant já defendera; nesse sentido, sua posição não se distancia da teoria tradicional do direito natural ${ }^{8}$.

A partir dessa teoria do Estado, Schopenhauer critica os filósofos alemães contemporâneos acusando-os de terem deturpado inteiramente o sentido da teoria do direito natural. Com isso, segundo Schopenhauer, as claras e simples relações da vida teriam sido tornadas incompreensíveis enquanto que as coisas nelas mesmas seriam simples e apreensíveis - simplex sigillum veri, frase constantemente repetida pelo autor. Aqui, a crítica à verborragia filosófica se junta à defesa de uma certa concepção do Estado cuja base é um certo pessimismo antropológico, ou ao menos o pressuposto de que, no geral, o homem jamais supera seu egoísmo.

Em minha obra principal (vol. 2, capítulo 47) mostrei que o Estado é essencialmente uma mera instituição de proteção de todos contra-ataques externos e dos indivíduos entre si. Disso se segue que a necessidade do Estado repousa, em última instancia, na reconhecida injustiça do gênero humano, sem o que não se teria pensado em nenhum Estado, pois ninguém temeria prejuízo a seu direito e uma mera reunião contra os ataques de animais selvagens ou dos elementos naturais teria uma fraca semelhança com um Estado. Desse ponto de vista vê-se claramente a trivialidade e a platitude dos filosofastros que, em discursos pomposos, apresentam o Estado como o fim supremo e a flor da existência humana,

está inseparavelmente unida à do país; deste modo, ela não pode, pelo menos nos negócios importantes, procurar o seu bem fora do bem público. Daí vem a força e a superioridade da monarquia hereditária". Ibid., p. 406.

${ }^{8}$ Cf. CATTANEO, Schopenhauers Kritik der Kantischen Rechtslehre, p. 405: "De fato, Schopenhauer chega, pela sua ênfase no significado da doutrina do direito enquanto interdição da injustiça, para evitar o sofrimento, exatamente lá onde Kant já havia, por um outro caminho, chegado. Embora critique a opinião de Kant de que o Estado e o direito constituem as condições para uma conduta moral justa e livre, Schopenhauer concorda com ele na distinção entre o direito, que é coercitivo, e a moral, que não pode ser objeto de coerção; isso significa que ambos, Schopenhauer $e$ Kant, são representantes do liberalismo clássico e defensores do estado de direito, e que ambos se distanciam da posição de Hegel, que considera o Estado como a fonte da moralidade (Moralität) ou como 'substância ética"'. 
com o que oferecem uma apoteose do filisteísmo (P II, Cap. 9, \123, p. 265).

Por fim, podemos falar propriamente em pessimismo na teoria política de Schopenhauer tendo em vista, por um lado, a restrição da atividade política entendida como capacidade para a criação de algo verdadeiramente novo e, por outro, seu olhar desesperançado para possíveis melhorias mínimas no modo de vida comum das sociedades modernas. Esse duplo pessimismo está contido na passagem final do $\ 62$ de sua obra principal:

No Estado, portanto, reconhecemos o meio pelo qual o egoísmo, servindo-se da faculdade da razão, procura evitar as suas próprias consequências funestas que se voltam contra si, e, assim, cada um promove o bem-estar geral, porque dessa forma assegura o seu bem-estar particular. Se o Estado alcançasse seu objetivo completamente, então, em certa medida, visto que conseguiria cada vez mais dominar a natureza restante ao empregar as forças humanas nele reunidas, poderia ser conquistado algo parecido com um reino utópico, devido à remoção de todo mal. Contudo, de um lado o Estado sempre permaneceu muito distante desse fim; de outro, restariam inumeráveis outros males absolutamente essenciais à vida, mantendo-a pois em sofrimento; e mesmo se de fato todos os males fossem erradicados, o tédio de imediato ocuparia cada lugar deixado vazio por eles; ademais, mesmo as disputas e as discórdias entre os indivíduos nunca são totalmente suprimidas pelo Estado, pois, proibidas nas grandes coisas, desenrolam-se nas pequenas; por fim, Eris, que foi com felicidade banida do interior, volta-se para o exterior: expulsa do conflito dos indivíduos por meio da instituição estatal, retorna no exterior como guerra entre os povos e então exige, no total e num só pagamento, como débito acumulado, sacrifícios sangrentos, os quais se lhe haviam negado ao recorrer-se a astuta precaução. Sim, supondo-se que tudo isso fosse ao fim ultrapassado e posto de lado por uma prudência acumulada pela experiência de milênios, o resultado seria a efetiva superpopulação de todo o planeta, cujo horrível mal só uma imaginação audaciosa poderia representar-se (W I, \62, pp. 413-4, trad. Cit., p. 406).

\section{A recepção da filosofia de Schopenhauer em termos políticos: entre conservadorismo e crítica social}

Tendo exposto os elementos básicos da teoria política de Schopenhauer, podemos fazer, a título de conclusão, um panorama esquemático de algumas das mais importantes recepções de sua filosofia no que diz respeito às consequências políticas de seu pensamento. Esse é um passo importante para construir uma reflexão razoavelmente séria e profunda sobre a relação mais ampla entre pessimismo e política.

Podemos começar esse esboço tomando como ponto de partida justamente o contexto em que as expressões "esquerda e direita", "conservador e progressista" têm sua conotação original, a saber, a França do século dezenove, onde de fato estava 
sempre em jogo a tomada de partido a favor ou contra a revolução do século anterior e onde, portanto, as consequências políticas das ideias jamais poderiam ser deixadas de lado. A presença constante de Schopenhauer na literatura e na filosofia francesa do final do século dezenove se deve a várias razões, mas uma das mais importantes é, sem dúvida, a permeabilidade do pessimismo ao reacionarismo. O pessimismo em geral dificilmente se concilia com o pensamento político progressista, muito menos com o discurso político de esquerda, em suas diversas roupagens. Crença numa natureza humana imutável, na inevitabilidade da decadência, descrença na política, crítica ao pensamento utópico, apego a certa sensibilidade romântica, desprezo pela história, descrédito a respeito do poder das "ideias", individualismo, etc. Tudo isso parece levar água ao moinho dos conservadores ${ }^{9}$. E isso tornou Schopenhauer uma referência para autores relevantes como Bourget, Guy de Maupassant, Baudelaire, entre outros, e nomes menos conhecidos como Brunetière e Charles Renouvier. É verdade que os primeiros leitores de Schopenhauer na França, como ChallemelLacour e Auguste Burdeau eram republicanos convictos, mas logo surgiram comparações que aproximaram Schopenhauer dos principais pensadores reacionários, como Joseph de Maistre e Chateaubriand. Nesse sentido, a análise de René-Pierre Colin foi certeira: "Schopenhauer, até aqui aliado involuntário da esquerda, iria ser anexado pela direita"10. Brunetière e Charles Renouvier vincularam o pessimismo de Schopenhauer ao pessimismo político de Pascal e à melancolia antirrevolucionárias de Joseph de Maistre. Com isso, a voga do pessimismo que invadiu a cena literária parisiense na década de 1880 pode ser descrita como o entrecruzamento dessa recepção conservadora de Schopenhauer com o decadentismo de Paul Bourget e Guy de Maupassant. A corrente de pensamento contrarrevolucionária, antimoderna e até mesmo anti-iluminista, descrita por Compagnon, preparou o sucesso de Schopenhauer no fin de siècle: "Um sopro de mal do século uma vez mais fulminava a juventude, que reagia à Comuna e ao triunfo do oportunismo republicano como havia feito depois da queda do Império e durante a Restauração"11.

Além do caso de Nietzsche, cuja complexidade repele qualquer juízo superficial ${ }^{12}$, e que por essa razão, passo ao largo, vale mencionar em linhas gerais, alguns elementos da recepção conservadora de Schopenhauer na Alemanha. Assim como na França, embora a primeira recepção tenha se dado sobretudo por autores progressistas, admite-se que a popularidade de Schopenhauer a partir da publicação dos Parerga e Paralipomena em 1851 se deveu sobretudo à conjuntura contrarrevolucionária da Alemanha depois de 1848. Nessa direção, Karl Löwith

\footnotetext{
${ }^{9}$ Sobre isso ver o livro COMPAGNON, Os antimodernos: De Joseph de Maistre a Roland Barthes.

${ }^{10}$ COLIN, Schopenhauer en France. Un mythe naturaliste, p. 128. Apud. COMPAGNON, Op. Cit., p. 89.

11 COMPAGNON, Op. Cit., p. 89.

12 Remeto ao estudo de LOSURDO, Nietzsche, o rebelde aristocrata. Revan, 2009.
} 
afirmou que a acolhida da obra de Schopenhauer só foi possível a partir da apatia em que se encontrava a intelectualidade alemã depois da derrota da Revolução de 1848. Ao cavar um fosso entre o significado fundamental da ética e as preocupações políticas e sociais, o filósofo de Danzig teria construído uma moral subjetiva, capaz apenas de oferecer um sucedâneo para a individualidade burguesa deprimida pela decadência do sistema capitalista na Alemanha e a conjuntura política repressiva. Daí a atualidade repentina do estoicismo dos Aforismos para a sabedoria de vida, cuja relevância está vinculada ao horizonte de bloqueio da práxis política, assim como já havia ocorrido quando do surgimento da escola no século III a. C. Anacronismos na história intelectual da negação.

$\mathrm{Na}$ virada do século e como continuação da cultura decadentista do fim do século dezenove, autores radicalmente conservadores como Ludwig Klages e Oswald Spengler desenvolveram filosofias pessimistas que, ainda que nem sempre em estrito diálogo com Schopenhauer, levaram adiante algumas das consequências de sua crítica do otimismo progressista. Se num primeiro momento, a crítica desses autores ao potencial destrutivo do avanço tecnológico da sociedade burguesa moderna, capitalista e democrática se assemelha em algum momento à crítica da esquerda socialista à mesma sociedade, ambas as tendências se separam em relação à concepção de história e à recusa de qualquer perspectiva emancipadora para a humanidade em geral. Além de elementos racistas e imperialistas, o pensamento desses autores, que reconhecidamente influenciaram Heidegger, desenvolvem uma estranha combinação de pessimismo cultural e otimismo do poder, uma negação da perspectiva de uma emancipação universal do ser humano e uma rejeição à vida moderna "burguesa", uma busca por autenticidade calcada na perseguição de certo ideal estético ${ }^{13}$. No caso de Spengler, porém, sua estética do monumental e do sublime, apesar de seu pessimismo histórico em larga escala, permite ver ao menos a plausibilidade da tese aparentemente disparatada de Lukács de um vínculo entre a crítica pessimista de Schopenhauer e Nietzsche e a pré-história do fascismo.

Nesse ponto cabe mencionar então a crítica de Lukács como expressão da mais completa rejeição ao pessimismo schopenhaueriano por motivos políticos. Apesar de exagerada, ela oferece o desafio incontornável para qualquer tipo de uso do pessimismo pela crítica de esquerda. A especificidade da interpretação do autor húngaro consiste não apenas na denúncia, de resto banal, do "irracionalismo" schopenhaueriano, mas na vinculação deste com o conservadorismo burguês. Sem se deter no movimento lógico do discurso de Schopenhauer, Lukács oferece uma interpretação da ideologia do intelectual burguês rentier, mais especificamente, do burguês do período da reação aos movimentos revolucionários de 1848: “O

\footnotetext{
${ }^{13}$ Cf. PAUEN, Pessimismus, p. 173 e seguintes.
} 
pessimismo de Schopenhauer é um reflexo ideológico do período da restauração”. ${ }^{14}$ Lukács minimiza o alcance das intuições schopenhauerianas ao considerá-las meramente como expressões de ranço de classe. Elas seriam apenas o resultado da radicalização social do individualismo burguês: "as atividades do indivíduo aparecem separadas de sua base social e voltadas pura e exclusivamente para dentro, cultivando as próprias peculiaridades e veleidades privadas como valores absolutos". ${ }^{15}$

A partir disso, Lukács vê em Schopenhauer a forma histórica, sintomática do "irracionalismo entre as revoluções", e como o "precursor do cosmopolitismo decadente". ${ }^{16}$ O filósofo teria, segundo Lukács, iniciado o movimento de liberação, através da ética, de todos os instintos negativos, antissociais e anti-humanos do homem, dando-lhes uma sanção moral, e apresentando-os se não como preceitos, pelo menos como "destino" do homem. O pessimismo metafísico aprofunda a alienação pois conduz ao quietismo e a passividade social: "enquanto o panteísmo desvia as mentes, objetivamente, da concepção religiosa do mundo, a filosofia de Schopenhauer, que professa ser ateísta, abre de novo o caminho para uma religião que não obriga a nada" ${ }^{17}$. Esse aspecto ficaria ainda mais claro, segundo Lukács, na concepção de tempo que a teoria do conhecimento de Schopenhauer oferece. Já que o tempo é definido pelo filósofo como uma mera forma da intuição, não tendo, portanto, qualquer realidade em si mesmo, não surpreende a negação radical de toda historicidade tanto da natureza como do mundo humano. Cabe observar que aqui Lukács reconstrói de modo preciso a oposição de Schopenhauer à filosofia de Hegel.

De um ponto de vista dialético, como o de Lukács, o pessimismo schopenhaueriano seria então a justificação filosófica do absurdo de toda atividade política e de todo o progresso, através da desvalorização de toda a forma de sociedade e de historicidade. O egoísmo burguês, outra característica do pessimismo é antes reforçado que negado, devido à concepção ética que confirma o isolamento do indivíduo. Tanto a teoria do conhecimento quanto a estética do filósofo conduziriam a esse fim. A negação do egoísmo presente na sociedade competitiva e individualista do capitalismo conduz a um isolamento igualmente individualista, para uma região sublime que paira acima do curso do mundo, da plebe e das obrigações sociais.

Ao esvaziar de sentido toda ação política, o pessimismo de Schopenhauer acabaria funcionando, intencionalmente ou não, como uma apologia indireta do capitalismo. Se a apologia direta do capitalismo, desvelada por Marx, consiste na eliminação das contradições sociais existentes ao apresentá-las como aparências

\footnotetext{
${ }^{14}$ LUKÁCS, El Asalto a la Rąón, p. 169.

${ }^{15}$ Ibid., p. 166.

16 Ibid., p. 169.

${ }^{17}$ Ibid., p. 177. É nessa direção que Lukacs sublinha o abismo que separa Schopenhauer e Hegel e contrapõe a lógica dialética do último à lógica metafísico-irracionalista do primeiro. Cf. Ibid., pp. 195-199.
} 
superficiais e passageiras, a apologia indireta se apresenta como uma forma bem mais elevada e tardia de apologia:

\begin{abstract}
enquanto a apologia direta se esforça em eliminar as contradições do sistema capitalista, de refutá-los por sofismas, de escamoteá-los, a apologia indireta, tomando como ponto de partida essas contradições, aceita sua existência como a de fatos inegáveis, mas lhes dando entretanto uma interpretação favorável, para manter o próprio capitalismo. Enquanto que a apologia direta se esforça em apresentar o capitalismo como a melhor ordem de coisas possíveis, como o ponto culminante da humanidade em marcha, atingido de uma vez por todas, a apologia indireta sublinha todos os lados ruins do capitalismo e seus horrores que ela considera não como características do capitalismo, mas de toda vida humana, da existência enquanto tal. Disso resulta que um combate levado a efeito contra esses horrores é por princípio não apenas condenado ao fracasso, mas também carece de todo sentido, pois equivale, segundo esta interpretação, a que o homem queira abolir sua própria natureza ${ }^{18}$.
\end{abstract}

Assim, ao invés de se voltar contra o capitalismo, verdadeira origem das contradições, a filosofia de Schopenhauer se volta contra o próprio mundo. Ela repudiaria a vida em todas as suas formas e o que restaria para nós seria apenas o nada. Ora, pergunta-se Lukács, é possível viver uma tal vida de acordo com essa filosofia? Ele responde afirmativamente, pois enquanto essa negação total não é realizada o que se vê é uma vida contemplativa plena de charme. Dessa forma, Lukács conclui fazendo o vínculo entre o pessimismo e o cinismo burguês:

o nada como perspectiva do pessimismo, como horizonte de vida, não pode impedir de modo algum o indivíduo, segundo a ética schopenhaueriana já exposta, de levar uma vida contemplativa plena de gozo (genussreiches). Pelo contrário, o abismo do nada, o fundo sombrio da carência de sentido da existência dá o tempero picante a este gozo da vida. Ademais, o aristocratismo afirmado da filosofia de Schopenhauer permitirá a seus fiéis de se sentir (isto é, de imaginar que eles estão) bem acima de uma plebe lamentável e tão limitada que ela ainda crê dever combater e sofrer para melhorar as condições da sociedade. O sistema de Schopenhauer - sistema engenhoso e harmoniosamente construído do ponto de vista da arquitetônica formal - ergue-se como um belo hotel moderno, dotado de todo conforto, à beira do abismo, do nada, da carência de todo sentido (ein schönes, mit allem Komfort ausgestattetes modernes Hotel am Rande des Abgrundes, des Nichts, der Sinnlosigkeit). E a diária contemplação do abismo, entre refeições esplêndidas, prazeirosamente degustadas, ou entre obras de arte preciosas, só pode realçar ainda mais o gozo desse conforto refinado ${ }^{19}$.

18 Ibid., p. 167.

${ }^{19}$ Ibid., p. 201. 
A partir de um livro publicado em 1980, Ludger Lütkehaus procurou desenvolver o conceito de uma esquerda schopenhaueriana, que a partir da recepção de autores como Mainländer e Horkheimer possibilitariam esboçar uma "filosofia crítica da miséria", como um contraponto à "miséria da filosofia" de Marx. De fato, Mainländer e Horkheimer são tipicamente "schopenhauerianos de esquerda" na medida em que se valem de argumentos pessimistas extraídos de Schopenhauer para desenvolver perspectivas críticas e emancipatórias que se afastam do conservadorismo de Schopenhauer.

A Filosofia da Redenção de P. Mainländer parte da inusitada proposta de síntese entre Ferdinand Lassalle e Siddhārtha Gautama Śākyamunis, ou seja, movimento operário social-democrata e ética compassiva budista! Se este é o projeto político de Mainländer se pode ver o quanto ele se afasta de seu mestre Schopenhauer. O primeiro volume de sua Filosofia da Redenção (1876) se encerra com uma "Crítica das doutrinas de Kant e Schopenhauer" e o capítulo final dessa parte, intitulado "Política" traz o seguinte comentário: "A miséria do povo é descrita [por Schopenhauer] de maneira excelente, mas isso apenas para dar relevo ao pessimismo. Ademais, Schopenhauer só ofereceu palavras de ódio e desprezo para o povo e seu esforço, e devemos nos afastar horrorizados dessa perversidade de disposição (Gesinnung) do grande homem". ${ }^{20}$ Nesse sentido, o filósofo irá elogiar Kant e os idealistas Fichte, Schelling e Hegel (o que certamente decepcionaria Schopenhauer) por terem concebido a história como o movimento da humanidade rumo ao estado ideal. ${ }^{21}$ Esse "estado ideal" é concebido por Mainländer de modo prático como um "princípio regulativo do socialismo", ${ }^{22}$ algo sobre o qual o movimento operário deve ter consciência para lutar por sua realização, mas que segundo sua metafísica, será apenas um momento intermediário para a redenção completa.

É no interior desse projeto filosófico que Mainländer procurará oferecer uma crítica da filosofia política de Schopenhauer. Como epígrafe ao capítulo supracitado o filósofo coloca ironicamente uma frase do próprio Schopenhauer: "Qualquer um, também o grande gênio, é em alguma esfera do conhecimento decididamente limitado"23. Segundo Mainländer, o "bem situado burguês Schopenhauer", deixou de ver que somente a vida num estado bem constituído e justo no que concerne à distribuição das riquezas poderia oferecer as condições necessárias para a redenção, não num estado de penúria e necessidade em que as preocupações vitais impediriam

\footnotetext{
${ }^{20}$ MAINLÄNDER, Die Philosophie der Erlösung, vol. I, p. 585.

${ }^{21}$ Cf. Idem, p. 587.

22 Antes de se suicidar, Mainländer escreveu um segundo volume da Filosofia da Redenção, que foi publicado em 1886 por sua irmã Minna Batz. Nele se encontra um texto intitulado Trếs discursos aos trabalhadores alemães, que também foi entregue ao movimento operário social democrata em forma de panfleto. Cf. MAINLÄNDER, Die Philosophie der Erlösung, vol. II, pp. 339 e seguintes.

23 Op. Cit, p. 583. A passagem encontra-se em P II, $\int 114$, p. 50.
}

Voluntas: Revista Internacional de Filosofia - periodicos.ufsm.br/voluntas - Santa Maria - Vol. 9, n. 2, jul.-dez. 2018 , p. 35-53. 
o livre curso do conhecimento - que é o que possibilita uma visão correta sobre a existência como um todo.

É sabido que Horkheimer foi grande leitor de Schopenhauer, e isso durante todo seu percurso intelectual, não apenas na fase final de seu pensamento a partir dos anos 60, em que de fato tentou articular uma nova formulação da teoria crítica partindo de Schopenhauer. Desde 1918 ele era membro da Schopenhauer Gesellschaft, e embora o nome do filósofo pouco apareça em suas primeiras obras, há relatos do seu constante interesse pela filosofia schopenhaueriana. Contudo, foi só a partir dos anos 50 que Horkheimer ofereceu contribuições efetivas para a interpretação da obra de Schopenhauer e o significado do seu legado. Horkheimer publicou cinco textos em vida sobre a filosofia de Schopenhauer: Schopenhaner e a sociedade (1955), A atualidade de Schopenhauer (1961), Religião e Filosofia (1967), Pessimismo hoje (1969) e O pensamento de Schopenhauer em relação à ciência e à religião de 1971. Do primeiro ao último texto é possível notar algumas diferenças fundamentais na abordagem de Horkheimer, pois se fica clara a vinculação entre os primeiros textos e as reflexões críticas sobre a "razão instrumental" e a "sociedade administrada", marcantes no pensamento de Horkheimer do pós-guerra, nos últimos é evidente o parentesco com os temas de sua filosofia tardia que flerta com uma recuperação da teologia por meio da temática do "anseio pelo inteiramente outro".

Apesar das variações em seu percurso intelectual, posições fundamentalmente pessimistas formam desde o início um elemento constante no pensamento de Horkheimer, por mais que se queira ver o pessimismo da fase tardia como uma radical mudança em relação às posturas críticas da década de 30. Esse elemento se refere ao caráter infundado da busca da felicidade, do sofrimento da natureza, das dores do passado e da transitoriedade do presente. Por isso, apesar de todo otimismo que possa ter o materialismo com relação à mudança das condições, "apesar de toda a valorização da felicidade que brota do esforço por mudança e da solidariedade, ele carrega consigo um traço pessimista. A injustiça passada é irremediável. Os sofrimentos das gerações passadas não encontram nenhuma compensação"24. O pessimismo aqui não se refere a uma teoria catastrófica, apocalíptica em relação ao presente e ao futuro, mas a fatos do passado, algo que não pode ser mais resgatado. Essa experiência do pessimismo não contradiz a convicção no caráter socialmente condicionado do bem-estar humano, pois também o sofrimento é causado por relações sociais e como tal deve ser combatido. Nesse sentido, o pessimismo também se compreende como socialmente condicionado, pois diz respeito a uma sociedade em que a solidariedade com aqueles que ela exclui, com os pobres e injustiçados, é negada: o pessimismo é assim negação da solidariedade negada. Se é assim, então o

${ }^{24}$ HORKHEIMER, Materialismo e Metafisica, p. 43. Cf. POST, Kritische Theorie und metaphysischer Pessimismus, p. 37.

Voluntas: Revista Internacional de Filosofia - periodicos.ufsm.br/voluntas - Santa Maria - Vol. 9, n. 2, jul.-dez. 2018, p. $35-53$. 
pessimismo de Horkheimer se distancia, pelo menos em sua fase inicial, de um pessimismo autocomplacente referido ao próprio sujeito, constantemente qualificado de "romântico", pois tenta unir a convicção de que "o núcleo mesmo da vida é o sofrimento e a morte", com a solidariedade presente na crítica social que visa a emancipação. Seria então essa convicção que justificaria a afirmação posterior de Horkheimer:

O pessimismo metafísico, momento implícito em todo pensamento genuinamente materialista, me foi familiar desde sempre. À obra de Schopenhauer devo meu primeiro contato com a filosofia: a relação com a doutrina de Hegel e de Marx, o desejo de compreender e de mudar a realidade social não resgataram, apesar do contraste político, minha experiência com a sua filosofia ${ }^{25}$.

Concluindo então esse mapeamento aqui apresentado como esboço para uma pesquisa mais ampla, percebe-se então a pertinência da proposta de L. Lütkehaus em falar de uma direita e uma esquerda schopenhauerianas. A abordagem original de Lütkehaus consiste em demonstrar que o quietismo não é a única consequência lógica do pessimismo de Schopenhauer o que permitiria ao menos esboçar o que ele chama de "uma filosofia crítica da miséria" ou "uma filosofia prática do como se" 26. Deixando de lado uma avaliação sobre a abordagem específica de Lütkehaus para escapar das armadilhas quietistas do pessimismo, é fato que autores como Mainländer e Horheimer desenvolveram perspectivas produtivas para o pessimismo enquanto filosofia prática. É evidente também, como fica especialmente claro no caso de Mainländer, que uma tal abordagem só é possível com um confronto crítico com o conservadorismo de Schopenhauer. Nesse sentido, a abordagem de Lütkehaus peca por desconsiderar completamente a possibilidade de interpretações não apenas à direita, mas claramente conservadoras e reacionárias da filosofia de Schopenhauer. Enfim, sua proposta é tentadora, mas caberia não deixar de notar que se é possível uma interpretação, digamos, progressista, de Schopenhauer, é também plausível, se não ainda mais razoável, uma abordagem conservadora de seu pessimismo, o que poderia permitir inclusive uma reflexão mais ampla sobre o vínculo entre $\mathrm{O}$ pessimismo e o pensamento conservador. Roger Scruton é o maior representante dessa vertente, que remete a uma tradição mais extensa de ideias antimodernas, contrarrevolucionárias e anti-iluministas. Schopenhauer é uma referência para essa tradição que remonta a Burke e De Maistre e um estudo sobre o pensamento

\footnotetext{
${ }^{25}$ Prefácio para a reedição de HORKHEIMER, Teoria Crítica I, p. 4.

${ }^{26}$ Cf. LÜTKEHAUS, Einleitung II: Pessimismus und Praxis, pp. 23-39, na qual a primeira seção - Ist der Pessimismus ein Quietismus? - coloca a questão do pessimismo ser um quiestismo, e na segunda seção - Ansätze zu einer Praxisphilosophie des $A l s-\mathrm{O} b$ - na qual ele introduz a possibilidade de formulação de uma moral do "Como-se" (Als-Ob). Cf. também do mesmo autor: "Esiste una sinistra schopenhaueriana? Ovvero: il pessimismo è un quietismo?".
} 
conservador e francamente reacionário seria tudo menos irrelevante para os dias que seguem.

\section{Referências bibliográficas}

BARBOZA, Jair. "Sabedoria de vida e práxis em Schopenhauer ou sobre uma possível "esquerda" schopenhaueriana". In: Filosofia alemã de Kant a Hegel. Organização de Marcelo Carvalho e Vinicius Figueiredo. São Paulo: ANPOF, 2013.

BRANN, Henry Walter. Schopenhauer und das Judentum. Bonn: Bouvier Verlag, 1975.

CATTANEO, Mario. "Das Problem des Strafrechts im Denken Schopenhauers", In: Schopenhauer Jahrbuch, n. 67, 1986, pp. 95-112.

CATTANEO, Mario. "Schopenhauers Kritik der Kantischen Rechtslehre" In: Schopenbauer Jahrbuch, no 69, 1988, pp. 399-407.

COLIN, René-Pierre. Schopenhauer en France. Un mythe naturaliste. Lyon: Presses universitaires de Lyon, 1979, p. 128. Apud. COMPAGNON, A. Os antimodernos: De Joseph de Maistre a Roland Barthes. Belo Horizonte: Ed. UFMG, 2011.

COMPAGNON, Antoine. Os antimodernos: De Joseph de Maistre a Roland Barthes. Belo Horizonte: Ed. UFMG, 2011.

EBELING, H. e LÜTKHAUS, L. (Orgs.). Schopenhauer und Marx: Philosophie des Elends, Elend der Philosophie? Königstein, Hain, 1980.

HAMLYN, D.W. "Eternal Justice”. In: Schopenhaner Jahrbuch, no 69, 1988, pp. 281-288.

HORKHEIMER, Max. Materialismo e Metafísica. In: Teoria Crítica I, Trad. de Hilde Cohn, São Paulo: Perspectiva, 2006.

HORKHEIMER, Max. "Schopenhauer und die Gesellschaft", In: Schopenhauer Jahrbuch no 36, Frankurt am Main, 1955, pp. 49-57.

HORKHEIMER, Max. "Die Aktualität Schopenhauers", In: Schopenhauer Jabrbuch, n ${ }^{\circ}$ 42, Frankurt am Main, pp. 12-25, 1961.

KROON, Annette Godart-van der. "Schopenhauer's Theory of Justice and its Implication to Natural Law”. In: Schopenhauer Jabrbuch, no 84, 2003, pp. 121-145.

KÜPPER, Georg. "Der Begriff des Unrechts bei Schopenhauer". In: Schopenhauer Jahrbuch, $\mathrm{n}^{\mathrm{o}}$ 74, 1993, pp. 103-114.

LOSURDO, Domenico. Nietæssche: o rebelde aristocrata: biografia intelectual e balanço crítico. Trad. Jaime A. Clasen. Rio de Janeiro: Revan, 2009.

LÖWITH, Karl. De Hegel à Nietəssche. Gallimard, Paris, 1969.

LUKÁCS, Georg. Schopenhauer. In: EBELING, H.; LÜTKHAUS, L. (orgs.) Schopenhauer und Marx: Philosophie des Elends, Elend der Philosophie? Königstein: Hain, 1980.

LUKÁCS, Georg. El Asalto a la Razón. Trad. de Wenceslao Roces. Barcelona, Grijalbo, 1976. 
LUKÁCS, Georg. História e Consciência de classe. Trad. de Rodnei Nascimento. São Paulo: Martins Fontes, 2003.

LÜTKEHAUS, Ludger. Einleitung II: Pessimismus und Praxis. Umrisse einer kritischen Philosophie des Elends. In: EBELING, H.; LÜTKEHAUS, L (Orgs.). Schopenhauer und Marx: Philosophie des Elends - Elend der Philosophie?. Königstein/Ts.: Hain, 1980, pp. 23-39.

LÜTKEHAUS, Ludger. "Esiste una sinistra schopenhaueriana? Ovvero: il pessimismo è un quietismo?” In: FAZIO, D.; KOßLER, M.; LÜTKEHAUS, L. (Orgs.). Arthur Schopenhaner e la sua scuola: Lecce: Pensa Multimedia, 2007.

MAINLÄNDER, Phillip. Philosophie der Erlösung. In: Schriften, org. por Winfried Müller-Seyfarth, Hildesheim, Zürich, New York, Olms Verlag, 4 vols, 1996.

MÜNKLER, Herfried. "Ein janusköpfiger Konservatismus: Arthur Schopenhauers politische Ideen”. In: Spierling, V. (org). Schopenhauer im Denken der Gegenwart. Munique: Piper, 1987, pp. 217-237.

PAUEN, Michael. Pessimismus: Geschichtsphilosophie, Metaphysik und Moderne von Nietzsche bis Spengler. Akademie Verlag, Berlin, 1997.

POST, W. Kritische Theorie und metaphysischer Pessimismus. Zum Spätwerk Max Horkheimers. München: Kösel Verlag, 1971.

ROSSET, Clément. Schopenhauer, Philosophe de L'absurde. Paris: PUF, 1967.

SCHOPENHAUER, Arthur. Sämtliche Werke. Editadas e comentadas criticamente por Arthur Hübscher, Wiesbaden, F. A. Brockhaus, 7 vols, 1972.

SCHOPENHAUER, Arthur. Parerga und Paralipomena. Zurique: Haffmans, 2 vols, 1988.

SCHOPENHAUER, Arthur. Sobre o Fundamento da Moral. Tradução de Maria Lúcia Cacciola, São Paulo, Martins Fontes, 1995.

SCHOPENHAUER, Arthur. Sobre a ética. (Capítulos 8 - 15 de Parerga e Paralipomena de Arthur Schopenhauer). Organização e tradução de Flamarion C. Ramos. São Paulo: Hedra, 2012.

SCHOPENHAUER, Arthur. O Mundo como Vontade e como Representação. Primeiro tomo. Tradução de Jair Barboza. 2a . edição, São Paulo: Unesp, 2015a.

SCHOPENHAUER, Arthur. O Mundo como Vontade e como Representação. Segundo tomo: Suplementos aos quatro livros do primeiro tomo Tradução de Jair Barboza. São Paulo: Unesp, 2015b. 